\title{
Primer reporte en Venezuela de Trichomonas tenax (Muller,1773) en secreción bronquial
}

\section{First report in Venezuela of Trichomonas tenax (Muller, 1773) in bronchial secretion \\ Primeiro relato de Trichomonas tenax na Venezuela (Muller, 1773) na secreção brônquica}

iD Luis Traviezo Valles ${ }^{1}$ iD Isbel González ${ }^{2}$

iD Eliana Fernández ${ }^{3}$

\section{Resumen}

Ilntroducción: El hábitat normal de Trichomonas tenax es cavidad bucal de personas con mala higiene oral, no existiendo reportes en Venezuela de este flagelado en órganos distintos. Caso clínico: Paciente masculino de 27 años que tras accidente en motocicleta es intervenido quirúrgicamente, lo que ameritó intubación y posteriormente traqueostomía, elementos que posiblemente facilitaron la broncoaspiración e infección pulmonar con este protozoario. Conclusión: Es la primera descripción en Venezuela de Trichomonas tenax en pulmón.

Palabras clave: Trichomonas, pulmón, secreción, Venezuela (Fuente: Descriptores en Ciencias de la Salud DeCS).

\section{Abstract}

Introduction. The normal habitat of Trichomonas tenax is the oral cavity of people with poor oral hygiene, there are no reports in Venezuela of this flagellate in different organs. Clinical case. A 27-year-old male patient who underwent surgery after a motorcycle accident, which required intubation and later tracheostomy, elements that possibly facilitated bronchial aspiration and lung infection with this protozoan. Conclusion. It is the first description in Venezuela of Trichomonas tenax in the lung.

Keywords: Trichomonas, lung, secretion, Venezuela (source: Health Sciences Descriptors DeCS).

\section{Resumo}

Introdução. O habitat normal de Trichomonas tenax é a cavidade oral de pessoas com má higiene bucal, não há relatos na Venezuela deste flagelado em diferentes órgãos. Caso clínico. Paciente do sexo masculino, 27 anos, operado após acidente de motocicleta, que necessitou de intubação e posterior traqueostomia, elementos que possivelmente facilitaram a aspi-
Correspondencia a:

1 Profesor Titular de Parasitología Médica. Universidad Centroccidental Lisandro Alvarado. Barquisimeto - Venezuela.

${ }^{2}$ Médico residente de Medicina Interna. Hospital Central Antonio María Pineda.

Barquisimeto - Venezuela.

${ }^{3}$ Licenciada en Bioanálisis.

Laboratorio Mascia.

Barquisimeto - Venezuela.

Email de contacto:

luisetraviezo@hotmail.com

Procedencia y arbitraje:

No comisionado, sometido a arbitraje externo

Recibido para publicación: 20 de septiembre del 2021

Aceptado para publicación: 30 de octubre del 2021

Citar como:

Traviezo Valles L, González I, Fernández E. Primer reporte en Venezuela de Trichomonas tenax (Muller,1773) en secreción bronquial. Recisa UNITEPC 2021;8(2):61-66.

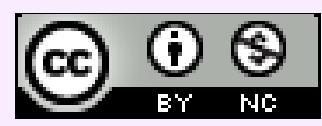

Esta obra está bajo una Licencia Creative Commons Atribución-NoComercial 4.0 Internacional. 
ração brônquica e infecção pulmonar por este protozoário. Conclusão. É a primeira descrição na Venezuela de Trichomonas tenax no pulmão.

Palavras-chave: Trichomonas, pulmão, secreção; Venezuela (fonte: Descritores em Ciências da Saúde: DeCS).

\section{Introducción}

Los principales parásitos asociados con abscesos bucales y lesiones mucocutaneas son los protozoarios Entamoeba gingivalis, Trichomonas tenax y Leishmania spp, igualmente se consiguen reportes de los helmintos Taenia solium (larvas) y Trichinella spiralis como causantes de daño en cavidad bucal (1).

Específicamente con respecto a Trichomonas tenax (T. tenax) el primer hallazgo fue reportado por O.F. Muller en 1773 en cultivos de sarro dental en agua, posteriormente en 1850 Hofle es el primero en observarlas directamente en muestras obtenidas de la placa dental (2).

Con microscopía fotónica se puede apreciar la morfología de este protozoario que en su ciclo solo presenta la forma de trofozoito, observándose su apariencia oval, elipsoidal o piriforme, con un tamaño de entre 4 y $12 \mu \mathrm{m}$ de longitud por 2 a $9 \mu \mathrm{m}$ de ancho $(1-10)$.

El trofozoito presenta una membrana delgada que rodea su cuerpo, un citoplasma finamente granulado que contiene vacuolas alimenticias llenas de bacterias, las cuales son su principal alimento, igualmente entre el núcleo y el extremo anterior se encuentran los blefaroblastos de donde nacen cuatro flagelos anteriores libres. $Y$ uno recurrente que emerge por el extremo anterior y recorre todo el cuerpo en dirección posterior, levantando la membrana citoplasmática y permitiéndole formar una membrana ondulante, careciendo este último flagelo de un extremo libre. Con respecto al núcleo el mismo es ovalado, con gránulos de cromatina gruesos y escasos (2-8).

El hábitat de T. tenax es el sarro dental, caries y saliva, de tal manera que, en la placa dental comparte este espacio principalmente con bacterias, pero también se pueden encontrar en esta zona, especies de hongos, micoplasmas y amibas como Entamoeba gingivalis $(2,3)$.

Los trofozoitos de Tricomonas tenax son tan resistentes y prolíferos que pueden sobrevivir hasta seis días en agua a temperatura ambiente y en cultivos se ha determinado su tiempo de duplicación en aproximadamente ocho horas, por división binaria longitudinal (2-8).

La incidencia de T. tenax en cavidad bucal a nivel mundial fluctúa entre 4 y $53 \%$, en Latinoamérica, por ejemplo, en Argentina se han señalado frecuencias de $24 \%$ en pacientes diabéticos. También investigaciones en Perú hacen referencia de un $24 \%$, mientras que en Venezuela los estudios son escasos y regionales, reportándose prevalencias como en el estado Zulia que oscilan entre $2 \%$ al $18,4 \%$, y en el estado Amazonas con $4 \%(1,2,6-10)$.

La presencia de Trichomonas tenax está relacionada con distintos procesos patológicos que ocurren tanto dentro como fuera de la cavidad bucal. Tal que también ha sido descrita en pacientes con absceso pulmonar o bronconeumonía, con cáncer pulmonar, en líquido cerebroespinal, en pus de absceso subhepático y en fibrosis quística 
de seno (1-3).

La presencia de Trichomonas tenax a nivel pulmonar, generalmente es por broncoaspiración y es muy rara, reportándose apenas seis casos en los Estados Unidos, tres en Francia, dos en Japón y apenas uno en Tailandia, Yugoslavia, Rusia y Chile (1-5).

\section{Materiales y Métodos}

Se desarrolla un estudio descriptivo con análisis retrospectivo de la historia clínica del paciente hospitalizado por traumatismos tras accidente de tránsito. Se hizo identificación taxonómica (morfología) del protozoario y se revisó la literatura existente para relacionarla con el caso.

\section{Descripción del Caso Clínico}

Paciente masculino de 27 años de edad y procedente de la población de Terepaima, municipio Palavecino del estado Lara, Venezuela, quien ingresa en fecha 30/06/2021, al área de Emergencia del Hospital Central Universitario Antonio María Pineda de Barquisimeto, luego de sufrir accidente en motocicleta. Presentando traumatismo craneoencefálico leve, trauma torácico y abdominal cerrados; complicado con hemoneumotórax izquierdo, tromboflebitis en miembro superior derecho y anemia leve normocítica normocrómica.

El 03/07/21 debido al trauma torácico y abdominal cerrado es intervenido quirúrgicamente, presentando en postoperatorio inmediato, trabajo ventilatorio que impidió la extubación en vista de complicarse con hemoneumotórax. En dicho contexto se mantiene en máquina de anestesia por no contar con disponibilidad en la unidad de cuidados intensivos, a la cual es trasladado posteriormente el 08/07/21, manteniéndose conectado a ventilación mecánica.

Se le realiza traqueostomía temprana, complicándose con neumonía asociada a ventilación mecánica e infección del tracto urinario, recibiendo antibioticoterapia según cultivo previo donde se identificó Klebsiella pneumoniae, tratándose con piperacilina-tazobactam, vancomicina y furosemida.

El paciente presentó gradual y lenta mejoría clínica por lo que, se procede al destete progresivo de ventilación mecánica desde el 24/07/21, manteniéndose con sistema de ventilación "T de Ayre" (descrito en 1937), desde el 27/07/2021, por lo que se decide traslado a unidad de menor complejidad (Medicina de Subagudos).

Días después se mantiene termodinámicamente estable, recibiendo antibioticoterapia de forma regular.

El 03/08/2021 se le toma muestra de secreción bronquial, con trampa de Lukens (secreción del traqueostomo) para hacer examen directo y cultivo en el laboratorio, reportándose polimorfonucleares abundantes, bacilos Gram negativos y blastoconidias gemantes escasas, igualmente sorprendió la observación numerosa del flagelado Trichomonas tenax.

En vista de la estabilidad del paciente se decide traslado a servicio de menor complejidad (Medicina de Hombres) para cumplimiento de tratamiento, especialmente se le indicó para las tricomonas, el metronidazol (500 mg por vía oral, cada 8 horas por 10 días). 


\section{Revista Científica de Salud UNITEPC}

ISSN $2520-9825$

El 10/08/2021 para determinar si el foco de diseminación de las tricomonas era la cavidad bucal del paciente. Se le toman muestras de sarro dental, en el proceso se aprecian varias caries, mala higiene bucal y lesiones liquenoides (trazas blancas en la mucosa) y al observar el directo con microscopía fotónica no se detectaron parásitos. Cabe señalar que, para el día de la toma de las muestras del sarro dental, ya el paciente presentaba seis días de tratamiento con metronidazol.

Otros elementos: padre diabético, paciente con una alimentación que no cumple con las leyes de Escudero, ingestión hipoproteica, hipercalórica, con predominio de carbohidratos.

Epidemiológicos: reside en vivienda de bloque, techo de acerolit, piso de cerámica, cuenta con los servicios básicos como agua por tuberías, electricidad, aseo urbano semanal y cloacas. Solo presenta como mascota un perro y señala la abundancia de diversidad de artrópodos, especialmente cucarachas, moscas y zancudos.

En vista a la mejoría clínica y la cura parasitológica es dado de alta en fecha 24/08/2021

\section{Discusión}

La tricomoniasis puede ser producida por tres especies de flagelados, Pentatrichomonas hominis cuyo habitad es intestino grueso humano, Trichomonas vaginalis, que se encuentra en tracto genitourinario y finalmente Trichomonas tenax que habita en cavidad bucal de personas con mala higiene oral (Figuras 1 y 2). No obstante, existen reportes de Trichomonas tenax en primates, caballos, perros y gatos, por lo que, no está claro su condición de parásito estenoxeno (3).

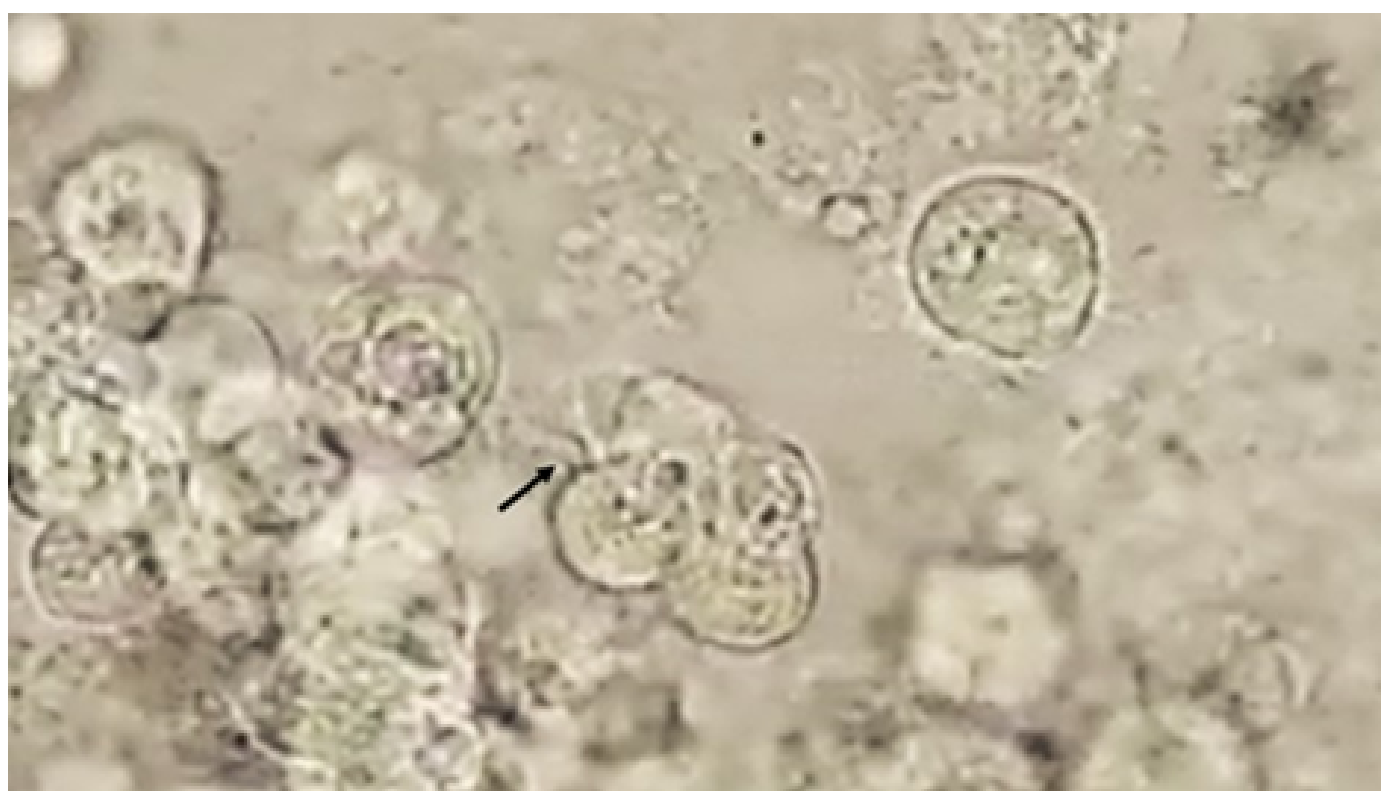

Figura 1. Trichomonas tenax en secreción bronquial, aumento de 400X. Se señalan los flagelos anteriores. Fuente: Microfotografía de los autores.

Trichomonas tenax ha sido asociada por algunos autores como causantes o corresponsables de gingivitis, periodontitis y de otros procesos patológicos que se presentan tanto dentro como fuera de los límites de la cavidad bucal. Tal que se ha reportado en ganglios linfáticos, glándulas mamarias, glándulas submaxilares, amígdalas, en hígado, pulmones y específicamente en bronquios, como lo reportado en el presente caso (1-8). 


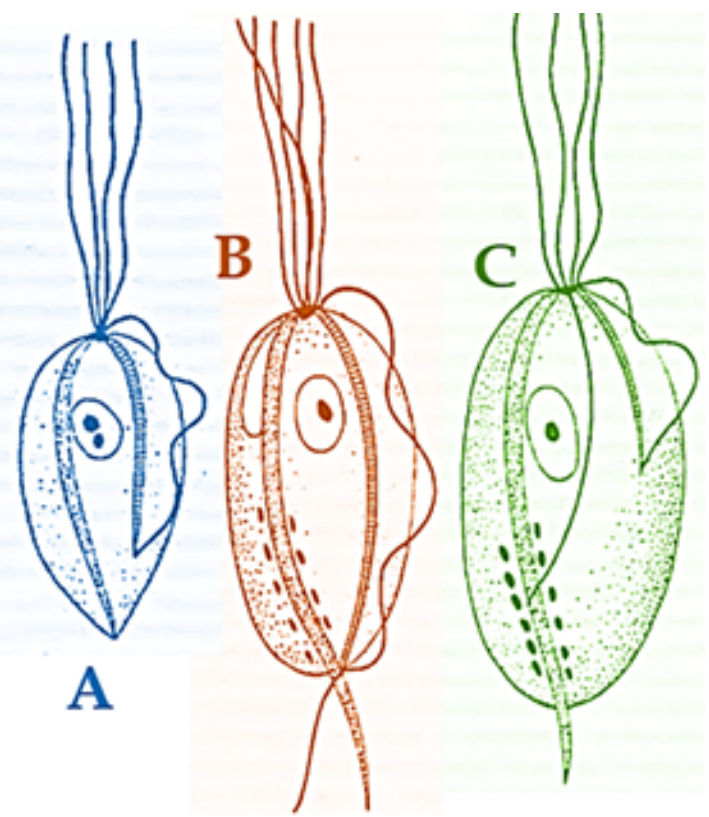

Figura 2. A- Trichomonas tenax, B - Pentatrichomonas hominis y

C-Trichomonas vaginalis. Fuente: Composición de los autores.

Con respecto a su capacidad patógena, se ha demostrado que $T$. tenax posee actividad lítica sobre los glóbulos rojos de humanos, caballos, conejos y ovejas. También se confirmó que el extracto total y las subfracciones S30 y P30 de T. tenax, presentan actividad de fosfolipasas que pueden influir en su actividad patogénica, ya que las fosfolipasas pueden producir zonas necróticas con destrucción tisular al liberar citotoxinas activas o sus precursores mediante exocitosis o autolisis (3).

Con respecto a su presencia en pulmón, en 1942 Glaubach y Guller señalaron el primer caso por neumonía por Trichomonas spp, posteriormente Trichomonas vaginalis se reportó en recién nacidos con neumonía neonatal, en pacientes con prácticas sexuales orogenitales (1-4).

El hallazgo de cualquiera de las tres especies de Trichomonas en pulmón, es extraordinariamente raro y en Venezuela es la primera vez que se señala a Trichomonas tenax en esta zona. Siendo esta especie la más frecuente de las tres especies en producir infección pleuropulmonar, lo cual generalmente se produce por aspiración de saliva desde la cavidad oral (1-4).

\section{Conclusiones}

El presente caso es raro, observándose compromiso pulmonar asociado a la presencia de Trichomonas tenax en este paciente, donde el rol patogénico de este flagelado necesita de mayores estudios. No obstante, por las evidencias de la mejoría del paciente después del tratamiento con metronidazol y el observar la cura clínica/parasitológica, sugiere que, en un futuro, será necesario la búsqueda de estos flagelados para identificarlos y administrar tratamiento específico para prevenir complicaciones y controlar infecciones.

\section{Conflicto de intereses}

Los autores declaran no tener ningún conflicto de interés. 


\section{Referencias Bibliográficas}

1. Nocito-Mendoza I, Vasconi MD, Ponce de León P, Zdero M. Entamoeba gingivalis y Trichomonas tenax en pacientes diabéticos. RCOE. 2003; 8(1):19-23.

2. Flores T. Estudio de protozoarios en la cavidad bucal humana: Entamoeba gingivalis (Gros 1849) y Trichomonas tenax (Muller, 1773). Kasmera. 1984; 12 (1-4): 27-54.

3. García E. Caracterización parcial de la principal actividad fosfolipasas tipo A1 y A2 en subfracciones de Trichomonas tenax. Tesis de Maestría en Ciencias. Universidad Autónoma de Nuevo León. 2019. Pp 66.

4. Cano Rodríguez A, Jiménez A. Derrame pleural por Trichomonas en paciente con bronquiectasias. Open Respir Arch. 2020; 2(3): 209-210.

5. Ramírez A, Palma A, Aviles E, Villarroel L. Empiema pleural causado por tricomonas. Rev Chilena de Cirugía. 2010; 62(3): 276-278.

6. Traviezo Valles L, Báez G, Rojas E, Iglesias F, Barragán A, Zubillaga V, Zavarce F. Entamoeba gingivalis, Trichomonas tenax Y Eimeria sp. en cavidad bucal de indígenas de Isla Ratón, estado Amazonas, Venezuela. Rev Venezolana Salud Púb. 2019; 7(2): 35-39.

7. Acurero E, Maldonado A, Maldonado C, Bracho A, Parra J, Urdaneta Y, Urdaneta M. Entamoeba gingivalis y Trichomonas tenax en cavidad bucal de pacientes de la Clínica Integral del Adulto de la Facultad de Odontología, Maracaibo, Venezuela. Rev Sociedad Venezolana Microbio. 2009; 29:122-127.

8. Hersh S. Pulmonary trichomoniasis and Trichomonas tenax. J. Med. Microbiol. 1985; 20: 1-10.

9. Wu Y, Ye Y, Yang Y, Yang W, Lin J, Cao K. Pyopneumothorax from coinfection by Trichomonas tenax and Geotrichum capitatum in a child from China: a case report. BMC Infect Dis. 2021; 21:842.

10. Bernaola-Paredes E, Gutiérrez F, Guillén A. Aislamiento de Trichomonas tenax en pacientes con periodontitis crónica al medio de cultivo de tioglicolato modificado. Kiru. 2012; 9(2):95-106. 